\title{
Studies on the Metabolic Fate of NK-104, a New Inhibitor of HMG-CoA Reductase (2): Absorption, Distribution, Metabolism, Excretion and Accumulation Following Repeated Oral Administration of ${ }^{14} \mathrm{C}-\mathrm{NK}-104$ in Rats
}

\author{
Hideki Fujino, Yoshihiko Tsunenari, Takashi KoIde, Masahiro Yonemitsu, \\ Yoshinobu Yanagawa* and Hideki Kimata \\ Tokyo Research Laboratories, Kowa Co., Ltd., Tokyo; \\ ${ }^{*}$ Central Research Institute, Nissan Chemical Industries, Ltd., Chiba
}

\begin{abstract}
Summary: NK-104 is a very potent competitive inhibitor of HMG-CoA reductase. In this study, the absorption, distribution, excretion and metabolism of ${ }^{14} \mathrm{C}-\mathrm{NK}-104$ were investigated during and after repeated oral administration to male rats at a daily dose of $1 \mathrm{mg} / \mathrm{kg}$ for nine days. The levels of radioactivity in the plasma at 0.5 and $24 \mathrm{hr}$ after daily dosing reached a steady state after the 4th administration, and levels were about 2 times higher than those after the 1st administration. High levels of radioactivity were detected in the liver during the repeated administration with maximum levels being 35-51 times higher than those in plasma. The level of radioactivity in other tissues after final administration was about 3 times that after the 1 st administration. The elimination of radioactivity from the tissues was rapid and complete by $144 \mathrm{hr}$ after the final administration. The excretion ratio of radioactivity in the urine and feces up to $144 \mathrm{hr}$ after the 9 th administration was 0.14 and $97.91 \%$, respectively. Unchanged NK-104 was mainly found in plasma during the repeated oral administration. Two major metabolites, $\mathrm{M}-6$ (pentenoic acid derivative) and $\mathrm{M}-8$ (propenoic acid derivative), as $\beta$-oxidation products of $\mathrm{NK}-104$, were found in heart and skeletal muscle after the repeated oral administration at levels $2-4$ times than after single administration. The radioactivity present in feces predominantly considered of the unchanged drug during the repeated administration. In conclusion, there was no significant accumulation of radioactivity due to repeated administration of ${ }^{14} \mathrm{C}-$ NK-104 to rats.
\end{abstract}

Key words: NK-104, HMG-CoA reductase inhibitor, Repeated oral administration, Absorption, Distribution, Metabolism, Excretion, Rat.

\section{Introduction}

In general, lowering the plasma levels of low-density lipoprotein (LDL) cholesterol while increasing high-density (HDL) cholesterol levels reduces the risk of coronary heart disease and atherosclerosis. NK-104 has been shown to be highly potent, specific inhibitor of HMG $\mathrm{CoA}$ reductase, the rate limiting enzyme in cholesterol biosynthesis. ${ }^{1)}$ Therefore, $\mathrm{NK}-104$ is expected to be developed as a therapeutic drug for hyperlipemia. The pharmacokinetics of $\mathrm{NK}-104$ in rat using ${ }^{14} \mathrm{C}$-labeled compound showed good absorption from the intestinal tract, specific distribution in the liver, and excretion in the feces via biliary excretion. However, the elimination of radioactivity from the heart and skeletal muscle was slower than that from plasma. ${ }^{2)}$ In the present study, the absorption, distribution, excretion and metabolism of ${ }^{14} \mathrm{C}-\mathrm{NK}-104$ to rat were investigated during and after repeated oral administration at a daily dose of $1 \mathrm{mg} / \mathrm{kg}$ for nine days. The effects of repeated administration on metabolic fate and accumulation were examined.

\section{Materials and Methods}

\section{Materials}

[Fluorbenzene-U-14C]NK-104 (Code CFQ 8596) was synthesized by Amersham Co., Ltd. (UK). The labeled position of ${ }^{14} \mathrm{C}-\mathrm{NK}-104$ was shown in a preceding report. ${ }^{2)}$ The specific radioactivity of labeled compound was $2.20 \mathrm{MBq} / \mathrm{mg}$, and its radiochemical purity was more than $96 \%$ during the experimental period. The unlabeled NK-104 and its metabolites (M-2, M-3, M-4, $\mathrm{M}-5, \mathrm{M}-6, \mathrm{M}-7, \mathrm{M}-8, \mathrm{M}-9, \mathrm{M}-10, \mathrm{M}-11$ and $\mathrm{NK}-104$ Lactone) which were isolated and identified in bile were synthesized by Nissan Chemical Industries, Ltd.. The postulated metabolic route of $\mathrm{NK}-104$ is shown in Fig. 1.

\section{Animals}

Wistar strain (specific pathogen-free) male rats at eight weeks of age, weighing 255-296 g were purchased 

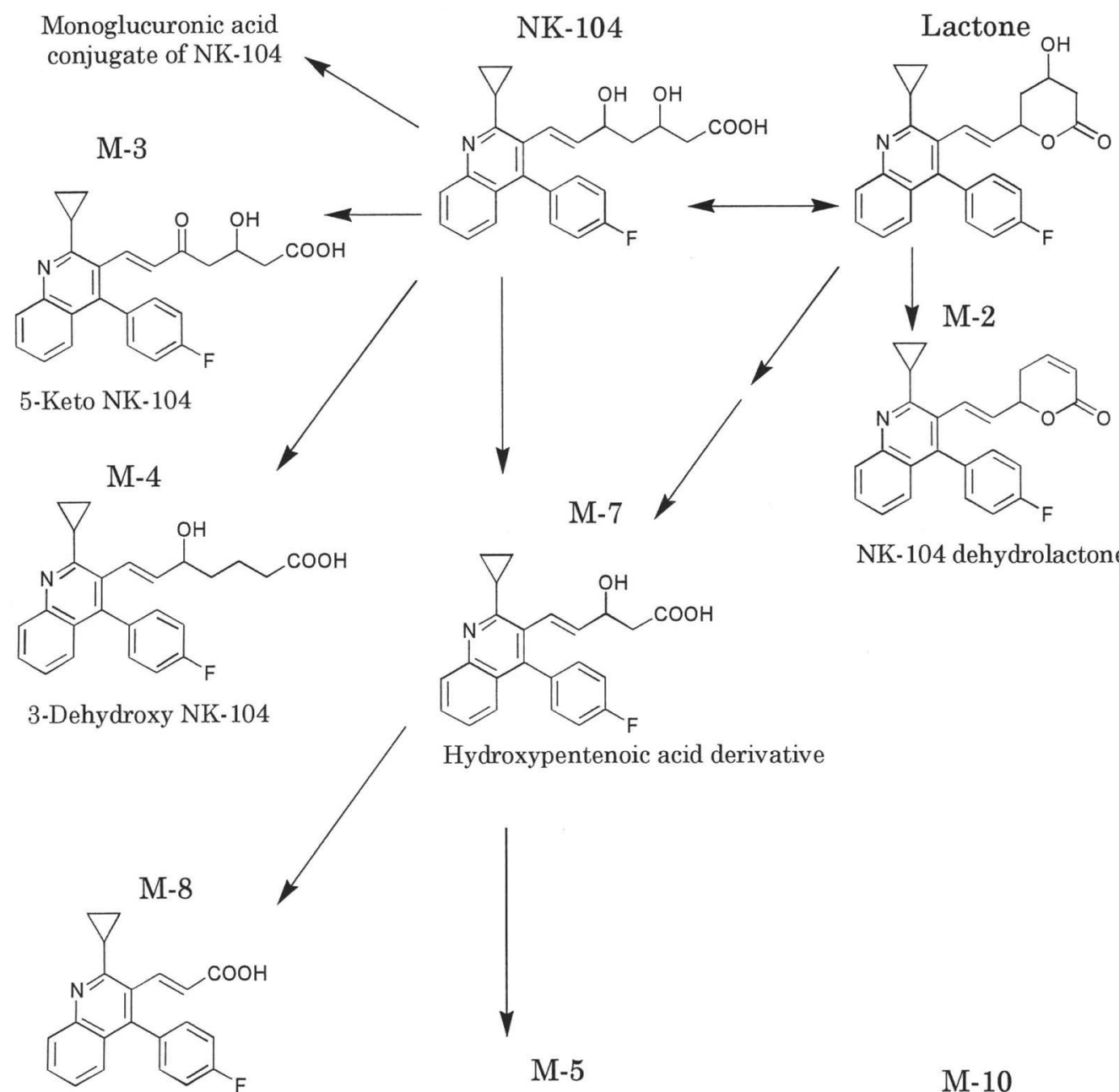

NK-104 dehydrolactone

Hydroxypentenoic acid derivative

Propenoic acid derivative<smiles>CC(C)(C)[C@@H]1C[C@@H]1c1nc2ccccc2c(-c2ccc(F)cc2)c1CCC(=O)O</smiles>

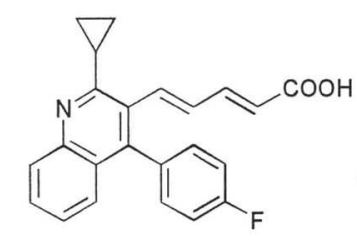

Pentadienoic acid derivative<smiles></smiles>

Propanoic acid derivative

Glucuronic acid conjugate of pentenoic acid derivative

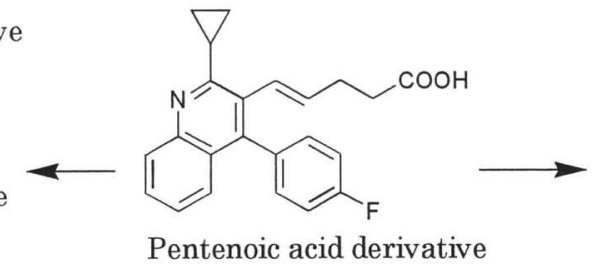

Pentenoic acid derivative

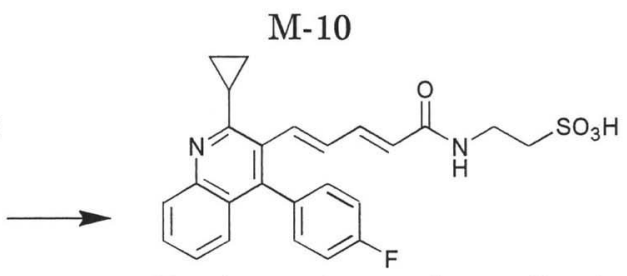

Taurine conjugate of pentadienoic acid derivative

M-11<smiles>O=C(CC/C=C/c1c(C2CC2)nc2ccccc2c1-c1ccc(F)cc1)NCCS(=O)(=O)O</smiles>

Taurine conjugate of pentenoic acid derivative

Fig. 1 Postulated metabolic route for NK-104 in rat.

from Japan Laboratory Animal Inc.. The diet and environmental conditions were the same as in our previous report. ${ }^{2)}$ Four animals were assigned to each test group.

\section{Administration of Drug}

The labeled NK-104 was dissolved as a solution in $0.5 \%$ sodium carboxymethyl cellulose solution to prepare a drug concentration of $0.25 \mathrm{mg} / \mathrm{ml}$. The dosing solution at a dose of $1 \mathrm{mg} / \mathrm{kg}$, was administered orally by 
gavage once a day for a maximum of 9 days to the rats. Animals were not fasted and the radioactivity dosed to rat was $2.20 \mathrm{MBq} / \mathrm{kg}$.

\section{Measurement of Radioactivity}

Radioactivity in each test sample was counted with a liquid scintillation counter (Tri-carb 1500; Packard) for $10 \mathrm{~min}$. The counting efficiency was corrected by the transformed spectral index of the external standard. If measured value was less than twice the background level, the concentration was taken as being below the limit of detection (not detected: n.d.).

\section{Repeated Administration Study}

\section{1) Determination of Radioactivity in Plasma}

Blood samples of about $0.3 \mathrm{~m} l$ were drawn from the jugular vein at 0.5 and $24 \mathrm{hr}$ after daily oral administration and at 48, 72, 96, 120 and $144 \mathrm{hr}$ after the 9th administration of ${ }^{14} \mathrm{C}-\mathrm{NK}-104$. Each sample was drawn into a heparinized tube and the plasma was separated by centrifugation. An aliquot of plasma $(0.1 \mathrm{~m} l)$ was dissolved in tissue solubilizer (Soluene-350; Packard). The radioactivity in each sample was measured after addition of scintillation cocktail (Hionic-Fluor; Packard).

\section{2) Determination of Radioactivity in Tissues}

Rats were anesthetized with pentobarbital sodium (Nembutal injection; Dainabot ${ }^{\circledR}$ and sacrificed by exsanguination from the abdominal vein at $0.5 \mathrm{hr}$ after the $1 \mathrm{st}$ and 9 th administration, at $24 \mathrm{hr}$ after the 1st, 6 th and 9th administration, and at 72 and $144 \mathrm{hr}$ after the 9 th administration, respectively. The following tissues were excised for examination: brain, hypophysis, eye ball, Harder's gland, thyroid gland, submaxillary gland, thymus, heart, lung, liver, kidney, adrenal, spleen, pancreas, abdominal fat, skeletal muscle, skin, bone marrow, testis and epididymis. The blood samples were collected with heparinized tubes from the abdominal vein for radioactivity counting. The plasma samples were obtained by centrifugation of remaining blood and an aliquot of plasma was used for the metabolite analysis. The heart was cut to half size to use for measuring tissue concentration and the remainder used for the analysis of metabolites. Radioactivity in each sample was measured with the solubilized method as described above.

3) Determination of Radioactivity in Urine and Feces

Rats were housed individually in glass metabolic cages (Metabolica, Sugiyamagen Iriki) during repeated oral administration of ${ }^{14} \mathrm{C}-\mathrm{NK}-104$. Urine and feces were collected at $24 \mathrm{hr}$ after daily administration and at intervals of $24 \mathrm{hr}$ up to $144 \mathrm{hr}$ after the 9th administration. Radioactivity of each urinary and fecal sample was measured as described previously. ${ }^{2)}$

\section{Analysis of Metabolites}

The plasma, heart, skeletal muscle, urinary and fecal samples obtained from rats after repeated oral administration of ${ }^{14} \mathrm{C}-\mathrm{NK}-104$ were used for the metabolite anal- ysis. The analysis of metabolites was carried out by HPLC off-line radioluminography ${ }^{3)}$ using a bioimage analyzer (BAS-2000; Fuji Film). The preparations of analytical samples and conditions for the measurement were as described in our previous report.2)

\section{Calculations}

The total radioactivity in each sample was converted to the equivalent value of $\mathrm{NK}-104$ and expressed as $\mu \mathrm{g}$ equivalent of $\mathrm{NK}-104 / \mathrm{g}$ or $\mathrm{ml}$. The radioactivity concentrations of $\mathrm{NK}-104$ metabolites were corrected by molecular weight. The polar and unknown metabolites were converted to the equivalent of $\mathrm{NK}-104$. The radioactivity of urinary and fecal samples was corrected to the $\%$ of dose. The data represent the mean \pm S.D. of four rats. The half-life values were estimated by using the least square method with actual data.

\section{Results}

\section{Radioactivity in Plasma}

Fig. 2 shows the plasma concentrations of radioactivity at 0.5 and $24 \mathrm{hr}$ after daily oral administration of ${ }^{14} \mathrm{C}-$ $\mathrm{NK}-104$ at a dose of $1 \mathrm{mg} / \mathrm{kg}$ to rats. The plasma concentrations at 0.5 and $24 \mathrm{hr}$ after the 1st administration were 0.048 and $0.015 \mu \mathrm{g}$ eq. $/ \mathrm{ml}$, respectively. Then, the plasma levels gradually increased along with the number of repeated doses and had approached the steady state by the 4 th administration. The plasma concentrations at 0.5 and $24 \mathrm{hr}$ after the 9 th administration were about 2 times those of the 1st administration. The half-life from 48 to $144 \mathrm{hr}$ after final dosing was $45.6 \mathrm{hr}$, indicating a slow clearance.

\section{Radioactivity in Tissue}

Table I shows the radioactivity concentrations in the tissues after the single, 6th and 9th administration of ${ }^{14} \mathrm{C}-\mathrm{NK}-104$ to rats. At $0.5 \mathrm{hr}$ after the single administration, the radioactivity level was high in the liver, 51 times that in the plasma. The concentrations in other tissues were almost the same or lower than that in the plasma. After the 9th administration, the concentrations in all tissues increased in comparison with those of the single administration. In particular, the radioactivity concentrations in the heart and skeletal muscle were 5 times and 4 times higher than for single administration, respectively.

The concentrations in all tissues after the 6 th administration increased in comparison with those following the single administration. On the other hand, no marked differences of radioactivity concentration were observed between the 6 th and 9 th administration groups. The level of radioactivity in the plasma was about 3 times higher than for the single administration. The radioactivity in tissues after repeated administration increased to within 4 -fold that after single administration, but was lower than in plasma.

After the 9th administration of ${ }^{14} \mathrm{C}-\mathrm{NK}-104$, the con- 


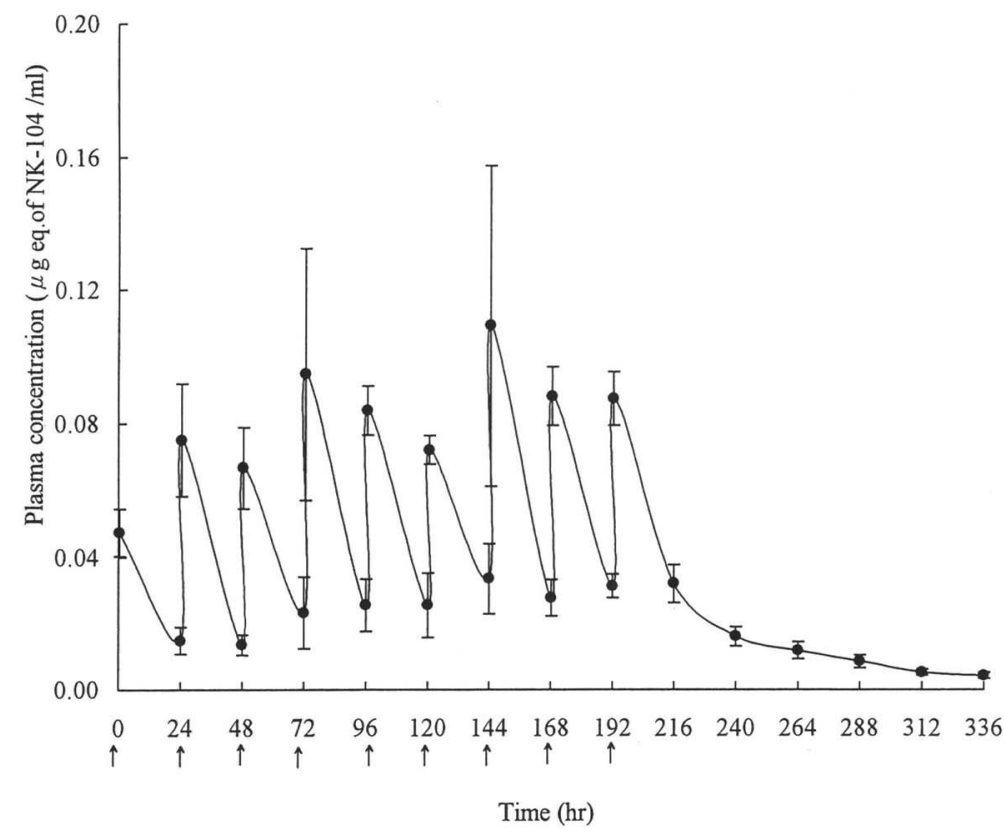

Fig. 2 Plasma concentration of radioactivity after repeated oral administration of ${ }^{14} \mathrm{C}-\mathrm{NK}-104$ at a dose of $1 \mathrm{mg} / \mathrm{kg} / \mathrm{day}$ to rats

Each point represents the mean \pm S.D. of four rats. $\uparrow$ represents the dosing points.

Table I Tissue concentration of radioactivity after single and repeated oral administration of ${ }^{14} \mathrm{C}-\mathrm{NK}-104$ to rats (dose: $1 \mathrm{mg} / \mathrm{kg} /$ day)

\begin{tabular}{|c|c|c|c|c|c|c|c|}
\hline \multirow{4}{*}{ Tissue } & \multicolumn{7}{|c|}{ Concentration ( $\mu$ g eq. of $\mathrm{NK}-104 / \mathrm{m} l$ or $\mathrm{g}$ ) } \\
\hline & \multicolumn{7}{|c|}{ Number of doses } \\
\hline & \multicolumn{2}{|c|}{ single dose } & \multirow{2}{*}{$\frac{6 \text { th dose }}{24 \mathrm{hr}}$} & \multicolumn{4}{|c|}{ 9th dose } \\
\hline & $0.5 \mathrm{hr}$ & $24 \mathrm{hr}$ & & $0.5 \mathrm{hr}$ & $24 \mathrm{hr}$ & $72 \mathrm{hr}$ & $144 \mathrm{hr}$ \\
\hline Plasma & $0.039 \pm 0.006$ & $0.009 \pm 0.003$ & $0.028 \pm 0.007$ & $0.079 \pm 0.024$ & $0.026 \pm 0.006$ & $0.007 \pm 0.002$ & $0.004 \pm 0.001$ \\
\hline Blood & $0.026 \pm 0.002$ & $0.006 \pm 0.002$ & $0.017 \pm 0.004$ & $0.053 \pm 0.015$ & $0.018 \pm 0.003$ & $0.007 \pm 0.001$ & $0.003 \pm 0.002$ \\
\hline Brain & $0.002 \pm 0.000$ & n.d. & $0.002 \pm 0.000$ & $0.004 \pm 0.000$ & $0.002 \pm 0.000$ & n.d. & n.d. \\
\hline Hypophysis & n.d. & n.d. & n.d. & $0.030 \pm 0.008$ & n.d. & n.d. & n.d. \\
\hline Eye ball & $0.002 \pm 0.000$ & $0.001 \pm 0.001$ & $0.003 \pm 0.001$ & $0.006 \pm 0.001$ & $0.004 \pm 0.001$ & $0.002 \pm 0.000$ & $0.001 \pm 0.001$ \\
\hline Harder's gland & $0.014 \pm 0.001$ & $0.009 \pm 0.002$ & $0.019 \pm 0.006$ & $0.038 \pm 0.005$ & $0.020 \pm 0.003$ & $0.005 \pm 0.001$ & $0.001 \pm 0.002$ \\
\hline Thyroid gl. & $0.011 \pm 0.007$ & n.d. & n.d. & $0.032 \pm 0.004$ & $0.010 \pm 0.007$ & & n.d. \\
\hline Submaxillary gl. & $0.014 \pm 0.003$ & $0.002 \pm 0.002$ & $0.008 \pm 0.003$ & $0.025 \pm 0.007$ & $0.007 \pm 0.001$ & $0.002 \pm 0.000$ & $0.001 \pm 0.001$ \\
\hline Thymus & $0.006 \pm 0.001$ & $0.001 \pm 0.002$ & $0.004 \pm 0.000$ & $0.011 \pm 0.002$ & $0.004 \pm 0.001$ & $0.001 \pm 0.001$ & n.d. \\
\hline Heart & $0.046 \pm 0.006$ & $0.069 \pm 0.028$ & $0.167 \pm 0.063$ & $0.238 \pm 0.066$ & $0.177 \pm 0.057$ & $0.034 \pm 0.006$ & $0.014 \pm 0.006$ \\
\hline Lung & $0.023 \pm 0.004$ & $0.004 \pm 0.002$ & $0.010 \pm 0.002$ & $0.039 \pm 0.011$ & $0.010 \pm 0.002$ & $0.004 \pm 0.001$ & $0.002 \pm 0.001$ \\
\hline Liver & $2.003 \pm 0.220$ & $0.065 \pm 0.016$ & $0.183 \pm 0.039$ & $2.766 \pm 1.122$ & $0.219 \pm 0.027$ & $0.090 \pm 0.015$ & $0.043 \pm 0.020$ \\
\hline Kidney & $0.109 \pm 0.018$ & $0.017 \pm 0.006$ & $0.041 \pm 0.010$ & $0.198 \pm 0.021$ & $0.044 \pm 0.009$ & $0.012 \pm 0.002$ & $0.006 \pm 0.002$ \\
\hline Adrenal & $0.026 \pm 0.007$ & n.d. & $0.010 \pm 0.003$ & $0.026 \pm 0.012$ & $0.020 \pm 0.014$ & n.d. & $0.002 \pm 0.003$ \\
\hline Spleen & $0.009 \pm 0.002$ & n.d. & $0.005 \pm 0.001$ & $0.017 \pm 0.004$ & $0.006 \pm 0.001$ & $0.003 \pm 0.001$ & $0.001 \pm 0.001$ \\
\hline Pancreas & $0.021 \pm 0.006$ & $0.002 \pm 0.003$ & $0.008 \pm 0.003$ & $0.037 \pm 0.014$ & $0.008 \pm 0.002$ & $0.002 \pm 0.000$ & $0.001 \pm 0.001$ \\
\hline Abdominal fat & n.d. & $0.007 \pm 0.005$ & $0.021 \pm 0.005$ & $0.029 \pm 0.007$ & $0.026 \pm 0.007$ & $0.010 \pm 0.003$ & $0.006 \pm 0.006$ \\
\hline Skeletal muscle & $0.008 \pm 0.001$ & $0.011 \pm 0.007$ & $0.018 \pm 0.001$ & $0.031 \pm 0.010$ & $0.026 \pm 0.011$ & $0.005 \pm 0.001$ & $0.002 \pm 0.001$ \\
\hline Skin & $0.006 \pm 0.001$ & $0.003 \pm 0.002$ & $0.010 \pm 0.001$ & $0.019 \pm 0.005$ & $0.011 \pm 0.002$ & $0.003 \pm 0.000$ & $0.002 \pm 0.001$ \\
\hline Bone marrow & $0.018 \pm 0.009$ & n.d. & n.d. & $0.023 \pm 0.008$ & $0.004 \pm 0.004$ & n.d. & n.d. \\
\hline Testis & $0.002 \pm 0.000$ & $0.006 \pm 0.002$ & $0.013 \pm 0.004$ & $0.015 \pm 0.005$ & $0.011 \pm 0.002$ & $0.003 \pm 0.001$ & $0.001 \pm 0.001$ \\
\hline Epididymis & $0.005 \pm 0.001$ & $0.004 \pm 0.001$ & $0.009 \pm 0.001$ & $0.013 \pm 0.003$ & $0.008 \pm 0.001$ & $0.003 \pm 0.001$ & $0.001 \pm 0.001$ \\
\hline
\end{tabular}

Each value represents the mean \pm S.D. of four rats.

n.d. : not detected 
Table II Cumulative excretion of radioactivity in urine and feces after repeated oral administration of ${ }^{14} \mathrm{C}-\mathrm{NK}-104$ to rats (dose: $1 \mathrm{mg} / \mathrm{kg} /$ day)

\begin{tabular}{ccrc}
\hline \multirow{3}{*}{ No. of doses } & \multicolumn{2}{c}{ Excreted radioactivity (\% of cumulative dose) } \\
\cline { 2 - 4 } & Urine & \multicolumn{1}{c}{ Feces } & \multicolumn{1}{c}{ Total } \\
\hline 1st & $0.03 \pm 0.01$ & $7.88 \pm 0.47$ & $7.91 \pm 0.48$ \\
2nd & $0.06 \pm 0.04$ & $18.18 \pm 0.51$ & $18.24 \pm 0.50$ \\
3rd & $0.08 \pm 0.04$ & $28.72 \pm 0.71$ & $28.80 \pm 0.73$ \\
4 th & $0.09 \pm 0.04$ & $39.17 \pm 0.90$ & $39.26 \pm 0.92$ \\
5 th & $0.10 \pm 0.04$ & $49.98 \pm 1.24$ & $50.08 \pm 1.26$ \\
6 th & $0.11 \pm 0.04$ & $61.68 \pm 1.27$ & $61.79 \pm 1.28$ \\
7 th & $0.12 \pm 0.04$ & $73.46 \pm 1.33$ & $73.58 \pm 1.34$ \\
8 th & $0.13 \pm 0.05$ & $84.78 \pm 1.56$ & $84.91 \pm 1.57$ \\
9 th & $0.14 \pm 0.05$ & $96.87 \pm 1.47$ & $97.00 \pm 1.46$ \\
\hline $48 \mathrm{~h}^{*}$ & $0.14 \pm 0.05$ & $97.68 \pm 1.24$ & $97.82 \pm 1.23$ \\
$72 \mathrm{~h}{ }^{*}$ & $0.14 \pm 0.05$ & $97.81 \pm 1.19$ & $97.95 \pm 1.19$ \\
$96 \mathrm{~h}{ }^{*}$ & $0.14 \pm 0.05$ & $97.87 \pm 1.16$ & $98.01 \pm 1.17$ \\
$120 \mathrm{~h}^{*}$ & $0.14 \pm 0.05$ & $97.89 \pm 1.16$ & $98.03 \pm 1.16$ \\
$144 \mathrm{~h}^{*}$ & $0.14 \pm 0.05$ & $97.91 \pm 1.15$ & $98.05 \pm 1.15$ \\
\hline
\end{tabular}

Each value represents the mean \pm S.D. of four rats.

$*$ : Hours after 9 th administration.

centration in the plasma declined with a half-life of 46.3 hr. Also, the disappearance of radioactivity from the liver was slow, indicating that the half-life for the liver was $52.1 \mathrm{hr}$. However, the radioactivity in various tissues declined more rapidly than in plasma. The radioactivity in a majority of tissues declined to nearly the detection limit at $144 \mathrm{hr}$.

\section{Excretion in Urine and Feces}

Table II shows the cumulative urinary and fecal excretion of radioactivity for $24 \mathrm{hr}$ after daily administration and up to $144 \mathrm{hr}$ after the 9 th administration. No essential change in the excretion of radioactivity was observed during the repeated administration. Radioactivity was mainly excreted into the feces, and the cumula- tive urinary and fecal excretions at $24 \mathrm{hr}$ after daily administration were 0.14 and $96.87 \%$ of dose after the 9 th administration, respectively. Finally, the total excretion of radioactivity was $98.05 \%$ of the cumulative administration.

\section{Metabolites in Tissue}

The typical HPLC radio-chromatograms of the extracts from the plasma, heart and skeletal muscle at 0.5 $\mathrm{hr}$ after 9th administration of ${ }^{14} \mathrm{C}-\mathrm{NK}-104$ to rat are shown in Fig. 3. Mostly unchanged NK-104 was found though NK-104 metabolites, M-6 (pentenoic acid derivative) and M-8 (propenoic acid derivative) were also detected in plasma at $0.5 \mathrm{hr}$ after the 9 th administration. On the other hand, $\mathrm{M}-6$ and $\mathrm{M}-8$ were mainly found in heart and skeletal muscle at $0.5 \mathrm{hr}$ after the 9th administration. In the radiochromatograms, no extractable unknown metabolites were found. Levels of M-3 (5keto NK-104 derivative) and M-10 (taurine conjugate of pentadienoic acid derivative) in plasma, and M-9 (propenoic acid derivative) in heart were negligible. The polar unknown metabolites of the unextracted fraction were also detected at only low concentration. No other metabolites were detected in plasma or either of these tissues.

\section{1) Metabolites in Plasma}

The concentrations of parent compound and its metabolite in the plasma are shown in Table III The concentration of unchanged NK-104 in the plasma at 0.5 and $24 \mathrm{hr}$ after single administration were 0.034 and $0.002 \mu \mathrm{g} / \mathrm{ml}$, and those levels after repeated administration were 1.5 times and 2.5 times higher than for the single administration, respectively. On the other hand, mainly the metabolites of NK-104, M- 6 and M- 8 were found after repeated administration. At $0.5 \mathrm{hr}$ after the 9th administration, the level of $\mathrm{M}-6$ was 2.5 times of the $0.002 \mu \mathrm{g} / \mathrm{m} l$ concentration after single administration. Also, the concentrations of M-6 and M- 8 were about $0.005 \mu \mathrm{g} / \mathrm{ml}$ at $24 \mathrm{hr}$ after repeated administration. No

Table III Concentration of unchanged NK-104 and its metabolite in plasma after repeated oral administration of ${ }^{14} \mathrm{C}-\mathrm{NK}-104$ to rats (dose: $1 \mathrm{mg} / \mathrm{kg} /$ day)

\begin{tabular}{|c|c|c|c|c|c|c|c|}
\hline \multirow{4}{*}{ Compound } & \multicolumn{7}{|c|}{ Concentration $(\mu \mathrm{g} / \mathrm{m} l$ or $\mathrm{g})$} \\
\hline & \multicolumn{7}{|c|}{ Number of doses } \\
\hline & \multicolumn{2}{|c|}{ single dose } & \multicolumn{2}{|l|}{6 th dose } & \multicolumn{2}{|c|}{ 9th dose } & \multirow[b]{2}{*}{$144 \mathrm{hr}$} \\
\hline & $0.5 \mathrm{hr}$ & $24 \mathrm{hr}$ & $24 \mathrm{hr}$ & $0.5 \mathrm{hr}$ & $24 \mathrm{hr}$ & $72 \mathrm{hr}$ & \\
\hline NK-104 & $0.034 \pm 0.006$ & $0.002 \pm 0.003$ & $0.008 \pm 0.006$ & $0.052 \pm 0.016$ & $0.005 \pm 0.004$ & n.d. & n.d. \\
\hline $\mathrm{M}-3$ & n.d. & n.d. & n.d. & $0.001 \pm 0.001$ & n.d. & n.d. & n.d. \\
\hline $\mathrm{M}-6$ & $0.002 \pm 0.001$ & n.d. & $0.005 \pm 0.006$ & $0.005 \pm 0.004$ & $0.004 \pm 0.003$ & n.d. & n.d. \\
\hline $\mathrm{M}-8$ & n.d. & n.d. & $0.005 \pm 0.004$ & $0.008 \pm 0.004$ & $0.005 \pm 0.003$ & n.d. & n.d. \\
\hline $\mathrm{M}-10$ & n.d. & n.d. & n.d. & $0.001 \pm 0.001$ & n.d. & n.d. & n.d. \\
\hline Polar & $0.003 \pm 0.001$ & $0.003 \pm 0.001$ & $0.007 \pm 0.001$ & $0.012 \pm 0.004$ & $0.009 \pm 0.003$ & $0.004 \pm 0.001$ & n.d. \\
\hline
\end{tabular}

Each value represents the mean \pm S.D. of four rats.

n.d. : not detected 

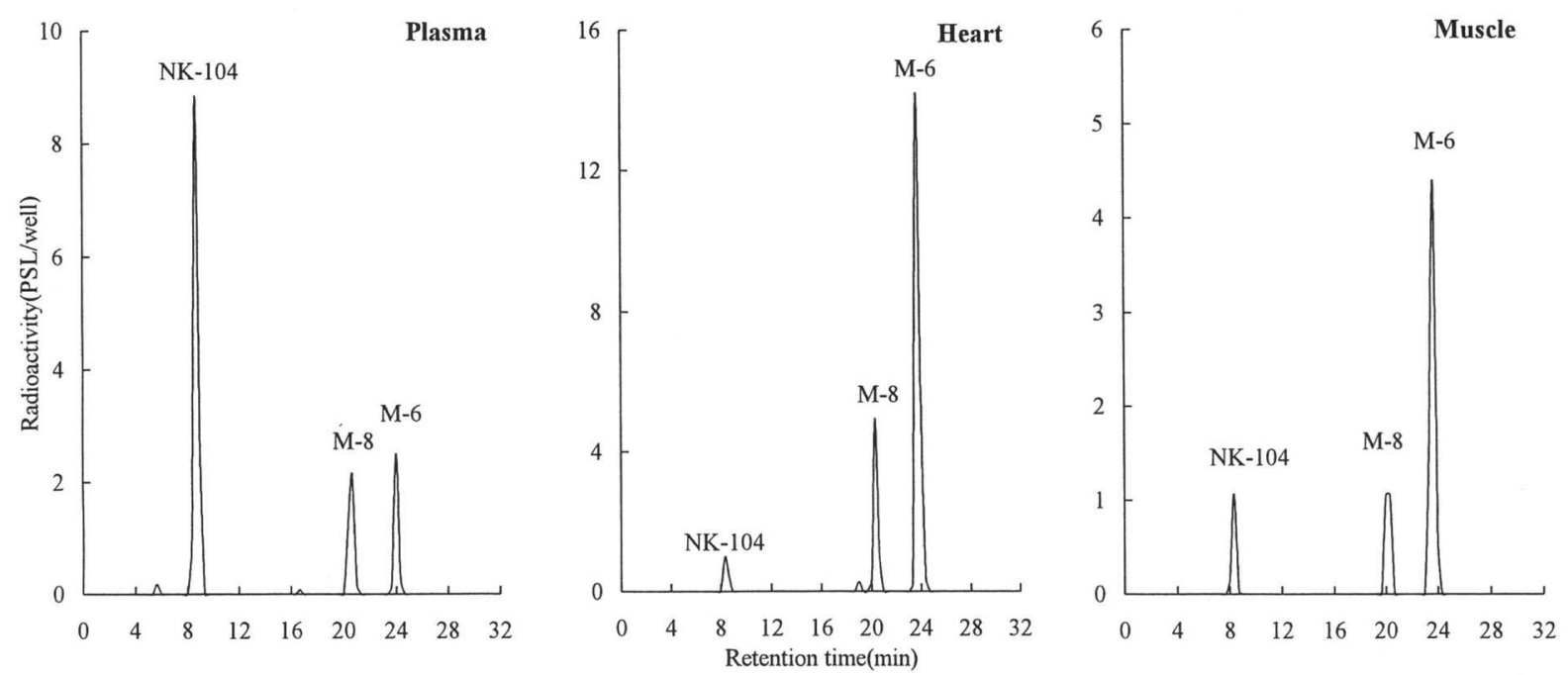

Fig. 3 HPLC-radiochromatograms of plasma, heart and skeletal muscle at $0.5 \mathrm{hr}$ after a 9 th oral administration of ${ }^{14} \mathrm{C}-\mathrm{NK}-$ 104 to rats (dose: $1 \mathrm{mg} / \mathrm{kg} /$ day).

Table IV Concentration of unchanged NK-104 and its metabolite in heart after repeated oral administration of ${ }^{14} \mathrm{C}-\mathrm{NK}-104$ to rats (dose: $1 \mathrm{mg} / \mathrm{kg} /$ day)

\begin{tabular}{|c|c|c|c|c|c|c|c|}
\hline \multirow{4}{*}{ Compound } & \multicolumn{7}{|c|}{ Concentration $(\mu \mathrm{g} / \mathrm{g})$} \\
\hline & \multicolumn{7}{|c|}{ Number of doses } \\
\hline & \multicolumn{2}{|c|}{ single dose } & \multirow{2}{*}{$\begin{array}{c}\text { 6th dose } \\
24 \mathrm{hr}\end{array}$} & \multicolumn{4}{|c|}{9 th dose } \\
\hline & $0.5 \mathrm{hr}$ & $24 \mathrm{hr}$ & & $0.5 \mathrm{hr}$ & $24 \mathrm{hr}$ & $72 \mathrm{hr}$ & $144 \mathrm{hr}$ \\
\hline NK-104 & $0.013 \pm 0.005$ & n.d. & n.d. & $0.015 \pm 0.007$ & n.d. & n.d. & n.d. \\
\hline$M-6$ & $0.023 \pm 0.009$ & $0.049 \pm 0.032$ & $0.069 \pm 0.030$ & $0.119 \pm 0.048$ & $0.082 \pm 0.024$ & n.d. & n.d. \\
\hline $\mathrm{M}-8$ & n.d. & $0.010 \pm 0.002$ & $0.037 \pm 0.009$ & $0.056 \pm 0.010$ & $0.038 \pm 0.007$ & $0.024 \pm 0.006$ & $0.008 \pm 0.005$ \\
\hline M-9 & n.d. & n.d. & $0.001 \pm 0.001$ & $0.002 \pm 0.002$ & $0.001 \pm 0.002$ & n.d. & n.d. \\
\hline Polar & $0.002 \pm 0.001$ & $0.002 \pm 0.001$ & $0.004 \pm 0.001$ & $0.007 \pm 0.002$ & $0.004 \pm 0.001$ & $0.002 \pm 0.000$ & $0.001 \pm 0.001$ \\
\hline
\end{tabular}

Each value represents the mean \pm S.D. of four rats.

n.d. : not detected

marked difference was noted in the composition ratios of these metabolites between the 6th and 9th administration. At $144 \mathrm{hr}$ after the 9th administration, the radioactivity was below the detection limit.

\section{2) Metabolites in Heart}

The concentrations of parent compound and its metabolite in the heart are shown in Table IV. At 0.5 $\mathrm{hr}$, no marked difference was noted in the concentrations of unchanged NK-104 $(0.013-0.015 \mu \mathrm{g} / \mathrm{g})$ between the single and 9th administration. Moreover, NK104 was not found at $24 \mathrm{hr}$ after single, 6 and 9th administration. On the other hand, M-6 and M-8 were mainly found in the heart at $24 \mathrm{hr}$ after each administration. At $0.5 \mathrm{hr}$ after 9 th administration, the concentration of M- 6 was about 5 times higher than that after the single administration. At $24 \mathrm{hr}$ after repeated administration, the concentrations of $M-6$ and $M-8$ were about 2 and 4 times higher than for the single administration, respectively, and no marked difference was noted in the composition ratios of these metabolites between the 6 th and 9 th administration. At 72 and $144 \mathrm{hr}$ after the 9th administration, $\mathrm{M}-8$ was mainly found in the heart and the concentration of M-8 moderately declined with a halflife of $53 \mathrm{hr}$.

\section{3) Metabolites in Skeletal Muscle}

The concentrations of parent compound and its metabolite in skeletal muscle are shown in Table V. No essential changes in the concentration of unchanged NK-104 were seen at $0.5 \mathrm{hr}$ after single and repeated administration-levels were very low. Furthermore, NK104 was not found at $24 \mathrm{hr}$ after each dosing. On the other hand, M-6 and M-8 were mainly found in the skeletal muscle at $24 \mathrm{hr}$ after repeated administration. In addition, the concentrations of M- 6 at 0.5 and $24 \mathrm{hr}$ after final repeated administration were 6.5 times and 1.7 times higher than for the single administration, respectively. Although the concentration of M-8 at $24 \mathrm{hr}$ after repeated administration was increased until the 6 th 
Table V Concentration of unchanged NK-104 and its metabolite in skeletal muscle after repeated oral administration of ${ }^{14} \mathrm{C}-$ NK-104 to rats (dose: $1 \mathrm{mg} / \mathrm{kg} /$ day)

\begin{tabular}{|c|c|c|c|c|c|c|c|}
\hline \multirow{4}{*}{ Compound } & \multicolumn{7}{|c|}{ Concentration $(\mu \mathrm{g} / \mathrm{g})$} \\
\hline & \multicolumn{7}{|c|}{ Number of doses } \\
\hline & \multicolumn{2}{|c|}{ single dose } & \multirow{2}{*}{$\begin{array}{c}\text { 6th dose } \\
24 \mathrm{hr}\end{array}$} & \multicolumn{4}{|c|}{9 th dose } \\
\hline & $0.5 \mathrm{hr}$ & $24 \mathrm{hr}$ & & $0.5 \mathrm{hr}$ & $24 \mathrm{hr}$ & $72 \mathrm{hr}$ & $144 \mathrm{hr}$ \\
\hline NK-104 & $0.005 \pm 0.002$ & n.d. & n.d. & $0.007 \pm 0.003$ & n.d. & n.d. & n.d. \\
\hline $\mathrm{M}-6$ & $0.002 \pm 0.002$ & $0.007 \pm 0.005$ & $0.010 \pm 0.003$ & $0.013 \pm 0.008$ & $0.012 \pm 0.005$ & n.d. & n.d. \\
\hline $\mathrm{M}-8$ & n.d. & n.d. & $0.005 \pm 0.001$ & $0.006 \pm 0.001$ & $0.006 \pm 0.001$ & $0.002 \pm 0.002$ & n.d. \\
\hline Polar & $0.001 \pm 0.000$ & n.d. & $0.001 \pm 0.000$ & $0.002 \pm 0.000$ & $0.002 \pm 0.001$ & $0.001 \pm 0.000$ & n.d. \\
\hline
\end{tabular}

Each value represents the mean \pm S.D. of four rats. n.d. : not detected

Table VI Composition of unchanged NK-104 and its metabolites in feces and urine after repeated oral administration of ${ }^{14} \mathrm{C}-\mathrm{NK}-104$ at a dose of $1 \mathrm{mg} / \mathrm{kg} /$ day to rats

\begin{tabular}{cccrr}
\hline \multirow{2}{*}{ Compound } & \multicolumn{3}{c}{ Composition (\% of radioactivity) } \\
\cline { 2 - 4 } Feces & NK-104 & $75.5 \pm 2.1$ & $75.5 \pm 2.6$ & $73.0 \pm 1.7$ \\
& Lactone & $2.0 \pm 0.3$ & $1.1 \pm 0.2$ & $1.5 \pm 0.2$ \\
M-3 & $1.8 \pm 0.1$ & $1.9 \pm 0.1$ & $1.9 \pm 0.5$ \\
M-6 & $0.9 \pm 0.8$ & $2.8 \pm 1.4$ & $3.6 \pm 1.5$ \\
M-7 & $0.2 \pm 0.1$ & $0.3 \pm 0.1$ & $0.3 \pm 0.2$ \\
M-8 & $0.2 \pm 0.1$ & $0.2 \pm 0.0$ & $0.2 \pm 0.1$ \\
M-10 & $1.0 \pm 0.2$ & $1.3 \pm 0.1$ & $1.2 \pm 0.3$ \\
M-11 & $0.9 \pm 0.1$ & $0.8 \pm 0.2$ & $1.2 \pm 0.4$ \\
Unknown & $3.7 \pm 0.6$ & $3.6 \pm 0.7$ & $5.1 \pm 1.7$ \\
Polar & $14.1 \pm 0.5$ & $12.5 \pm 1.2$ & $12.0 \pm 1.3$ \\
\hline Urine & NK-104 & $33.3 \pm 10.0$ & $5.4 \pm 6.6$ & $4.6 \pm 3.5$ \\
M-10 & $0.9 \pm 1.7$ & 0.0 & $1.7 \pm 2.5$ \\
M-11 & 0.0 & $5.0 \pm 6.1$ & $2.6 \pm 4.0$ \\
Unknown & $14.8 \pm 6.9$ & $34.1 \pm 2.6$ & $28.5 \pm 8.0$ \\
Polar & $50.7 \pm 4.5$ & $55.4 \pm 9.3$ & $62.7 \pm 5.3$ \\
\hline
\end{tabular}

Each value represents the mean \pm S.D. of four rats.

administration, no marked difference was noted in the composition of this metabolite between the 6th and 9th administration. From 24 to $72 \mathrm{hr}$ after final repeated administration, the concentration of $\mathrm{M}-8$ declined with a half-life of $30 \mathrm{hr}$.

\section{Metabolites in Feces and Urine}

Typical HPLC radio-chromatograms of the extracts from feces and urine after the 9 th administration of ${ }^{14} \mathrm{C}-$ NK-104 to rat are shown in Fig. 4. The composition of parent compound and its metabolite are shown in Table VI.

The relative composition of NK-104 in feces accounted for $75.5 \%$ of radioactivity within $24 \mathrm{hr}$ after the 1 st administration. As noticeable metabolites, NK-104 lactone and M-3 (5-keto NK-104) were slightly excreted in feces, and accounted for 2.0 and $1.8 \%$ of fecal radioactivity, respectively. The relative composition of M-6 increased gradually during repeated administration, indicating that the excretion of $\mathrm{M}-6$ after the 9th administration was 4 times higher than that after the 1st administration. Concentration of M-7 (hydroxypentenoic acid derivative), M-8, M-10 and $\mathrm{M}-11$ (taurine conjugate of pentenoic acid derivative) in feces were negligible and the other metabolites were not found. No difference was noted in the relative amounts of parent compound and the other metabolites in the feces between the 1st and repeated administration. After enzymatic hydrolysis of feces, no significant difference was noted in the relative composition of parent compound and metabolites in comparison with the non-treated feces (data not shown.). The relative composition of NK-104 accounted for $33.3 \%$ of radioactivity in the urine after the 1 st administration. However, the relative composition of urinary metabolites was less than $5 \%$ of radioactivity during the repeated administration.

\section{Discussion}

The absorption, distribution, excretion and metabolism were investigated after repeated administration of ${ }^{14} \mathrm{C}-\mathrm{NK}-104$ once a day for a maximum of 9 days to rats at a dose of $1 \mathrm{mg} / \mathrm{kg}$.

The mean plasma concentrations of radioactivity at $0.5 \mathrm{hr}$ after the 4 th administration increased to about $2^{-}$ fold the $0.048 \mu \mathrm{g}$ eq. $/ \mathrm{m} l$ of the 1 st dosing. However, no marked variation was observed in the plasma levels at $0.5 \mathrm{hr}$ between the 4 th and 9 th administration, indicating that a steady state was attained by the 4 th dosing. Also, the plasma concentrations of radioactivity at $24 \mathrm{hr}$ after the repeated administration had reached a steady state by the 4 th dosing. In addition the half-life in the terminal phase after final repeated administration was about 2 times longer than for the single administration. ${ }^{2)}$ This phenomenon might be due to the increase of the concentrations in the heart and skeletal muscles, which showed relatively slow elimination of the radioactivity after single administration of ${ }^{14} \mathrm{C}-\mathrm{NK}-104$. 


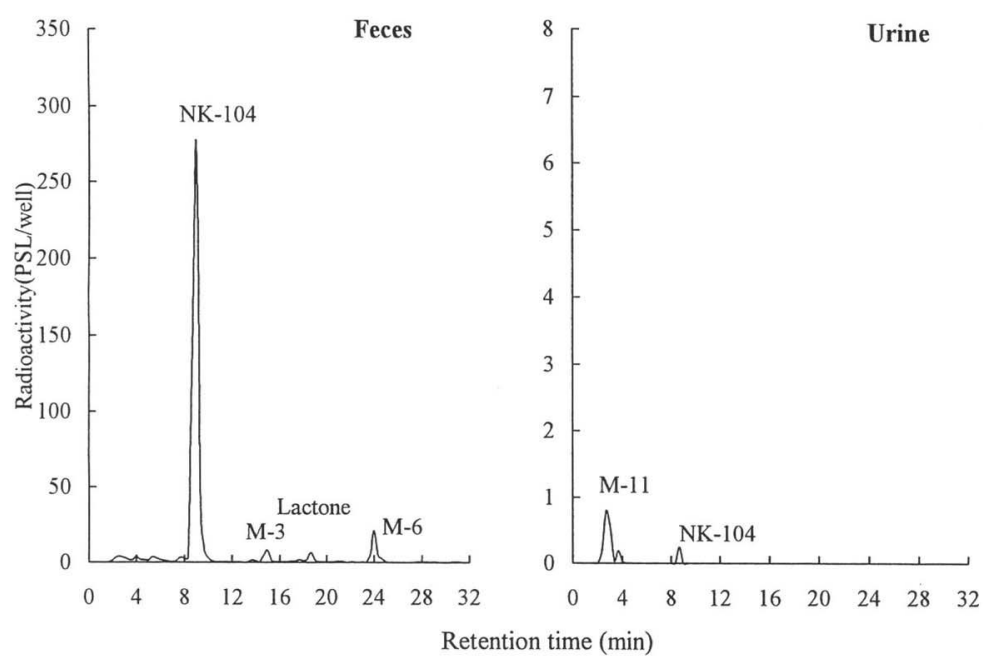

Fig. 4 HPLC-radiochromatograms of feces and urine after a 9th oral administration of ${ }^{14} \mathrm{C}-\mathrm{NK}-104$ to rats (dose: $1 \mathrm{mg} /$ $\mathrm{kg} /$ day).

The distribution of radioactivity in most tissues after the repeated administration of ${ }^{14} \mathrm{C}-\mathrm{NK}-104$ was of generally low affinity except for the liver. Although all the tissue concentrations of radioactivity at $24 \mathrm{hr}$ after the repeated administration increased in comparison with those of single administration, a steady state in each tissue was attained by the 6 th dosing in any case. The highest radioactivity among all tissues was observed in the liver. The levels at $0.5 \mathrm{hr}$ after single or 9th administration were 51 or 35 times than in plasma, respectively. Therefore, the selective distribution of NK-104 into the liver, which is the target organ of $\mathrm{HMG}-\mathrm{CoA}$ reductase inhibitor, may exhibit an efficacy in animall ${ }^{1)}$ and clinical studies. ${ }^{4)}$

Other HMG-CoA reductase inhibitors (statins) have been reported to show retention of radioactivity in the heart and skeletal muscle. In fluvastatin and cerivastatin, the radioactivity concentrations in these tissues at $24 \mathrm{hr}$ after repeated dosing were $5-16$ times higher than after single dosing. ${ }^{5,6)}$ In our previous study, ${ }^{2)}$ slow elimination of radioactivity was observed in the heart and skeletal muscle after oral administration of ${ }^{14} \mathrm{C}-\mathrm{NK}-104$ in rats. It is considered that M- 6 and M- 8 as metabolites of $\mathrm{NK}-104$, mainly present in these tissues at $24 \mathrm{hr}$ after repeated administration, approached a steady state on the 6th dosing in the present study. Although the concentrations of $\mathrm{M}-6$ and $\mathrm{M}-8$ in the heart at $24 \mathrm{hr}$ after single administration were 0.049 and $0.010 \mu \mathrm{g} / \mathrm{g}$, respectively, the levels at $24 \mathrm{hr}$ increased about 2 and 4 -fold until a steady state was attained after repeated administration. The concentrations of M-6 and M- 8 in the skeletal muscle had reached a steady state by the 6 th dosing. This suggested that the retention of $\mathrm{M}-6$ and $\mathrm{M}-8$ depended on the repeated administration of $\mathrm{NK}-104$ in the heart and skeletal muscle. These two metabolites are the products of $\beta$-oxidation of the heptenoic side chain of NK-104 and possess a mono-carboxylate moiety. It has been also reported that the mono-carboxylate transporter system plays an important role in the transport of short chain mono-carboxylic acids at plasma membrane. ${ }^{7)}$ In particular, as much mRNA of this transporter was expressed in the heart as in the skeletal muscle. ${ }^{8)}$ Therefore, it is suggested that $\mathrm{M}-6$ and $\mathrm{M}-8$ are transported across the plasma membrane of heart and skeletal muscle via the mono-carboxylate transporter, and the elimination of these metabolites from the tissues occurs at a moderate rate. Moreover, it was reported that $\beta$-oxidation was the major metabolic pathway for fluvastatin, ${ }^{9)}$ and the $\beta$-oxidation metabolite of the heptenoic side chain of fluvastatin which possesses a mono-carboxylate structure was the main metabolite found in rat. ${ }^{10)}$ The radioactivity retention of fluvastatin in the heart and skeletal muscle may relate to the transporter mechanism.

The radioactivity was excreted nearly quantitatively during $24 \mathrm{hr}$ after each dosing of ${ }^{14} \mathrm{C}-\mathrm{NK}-104$. The excretion ratios of radioactivity in the feces were constant and the urinary excretion was practically negligible during the repeated administration. The excretion profile was in good agreement with the single dosing in our previous study. ${ }^{2)}$ It has been reported that $75 \%$ of the radioactivity of administered ${ }^{14} \mathrm{C}-\mathrm{NK}-104$ orally was recovered in the bile as a main route of excretion in bile duct-cannulated rats. ${ }^{2)}$ This result indicates that NK104 and metabolites were excreted mainly in the feces via the bile in rats. In fact, excretion of radioactivity in bile was achieved at about $99 \%$ of the dose after intravenous administration as described. ${ }^{2)}$ The feces comprised mainly unchanged NK-104 and these results suggested that $\mathrm{NK}-104$ was poorly metabolized in the liver. Moreover, the relative amount of parent compound and its metabolites did not change significantly during repeated administration and no noticeable influence on metabolic fate was observed. These results indicated 
that enzyme induction dependent on repeated administration did not occur. In addition the increase in the relative composition of $\mathrm{M}-6$ in feces also might be a result of slow elimination from the heart and the skeletal muscle. Although trace of extractable and polar unknown metabolites in feces during repeated administration were detected, the excretion ratios were not changed.

In this study, the metabolites of NK-104 in plasma and tissues were determined with a HPLCradioluminography method that possesses high sensitivity and resolution for determining the metabolites of ${ }^{14} \mathrm{C}-$ $\mathrm{NK}-104$ in biological samples. In particular, this method was very useful for the determination of poorly metabolized compounds as metabolites of NK-104. NK-104 was metabolized via three major biotransformation routes, lactonization, $\beta$-oxidation of heptanoic acid side chain and conjugation of phase metabolism (Fig. 1). The lactonization product (lactone), $\beta$-oxidation products (M-6, M-7 and $\mathrm{M}-8)$ and taurine conjugation products $(\mathrm{M}-10, \mathrm{M}-11)$ were detected in feces. These results are in good agreement with the metabolic profile of the liver. ${ }^{2)}$ On the other hand, the $\beta$-oxidation metabolites of heptanoic acid side chain (M-6, M-8) were mainly found in the plasma, heart and skeletal muscle. These results indicated that the metabolites were mainly excreted into the bile, thus minimizing the systemic burden.

In conclusion, no great accumulation resulting from repeated administration of ${ }^{14} \mathrm{C}-\mathrm{NK}-104$ to rats was observed in the plasma and tissues in the present study. No difference was observed in the excretion profile for feces and urine during repeated administration. Furthermore, repeated administration has no influence on the metabolic fate of $\mathrm{NK}-104$.

\section{Reference}

1) Aoki T., Nishimura H., Nakagawa S., Kojima J., Suzuki H., Tamaki T., Wada Y., Yokoo N., Sato F., Kimata H., Kitahara M., Toyoda K., Sakashita M. and Saito Y.: Phar- macological profile of novel synthetic inhibitor of 3 hydroxy-3-methylglutaryl-coenzmeA reductase, $\mathrm{Ar}$ zneim. Forsch./Drug Res., 47 (8): 904-909 (1997).

2) Kimata H., Fujino H., Koide T., Yamada Y., Tsunenari Y. and Yanagawa Y.: Studies on the metabolic fate of NK104(1): Absorption, distribution, metabolism and excretion in rats, Xeno. Metab. Disp., (in press).

3) Baba S., Terasawa Y., Kimata H., Shinohara Y., Akira K. and Hasegawa H.: Application of radioluminography to off-line counting of radioactivity in high-performance liquid chromatographic elutes, J. Chromatogr., 663: 35-41 (1994).

4) Nakaya N., Kojima J., Kimata H., Kuwahata R. and Narushima H.: NK-104, Efficacy and tolerance of a new synthetic HMG-CoA reductase inhibitor in hyperchlesterolemic volunteers, XII International Symposium on Drug Affecting Lipid Metabolism, Houston, USA, 1995.

5) Masuda N., Akasaka I. and Ohtawa M.: Metabolic fate of Fluvastatin, an inhibitor of HMG $\mathrm{CoA}$ reductase (2): Transfer to the fetus and milk, and absorption, distribution and excretion after consecutive oral administration of ${ }^{14} \mathrm{C}-$ Fluvastatin in rats, Xeno. Metab. Disp., 10(4): 529 546 (1995).

6) Steinke W., Yamashita S., Tabei M., Ahr HJ., Beckermann B., Domdey-Bette A., Goller G., Schwarz T. and Siefert HM.: Cerivastatin, a new inhibitor of $\mathrm{HMG}-\mathrm{CoA}$ reductase-pharmacokinetics in rats and dogs, Jpn, Pharmacol. Ther., 24 (supple): 1217-1237 (1996).

7) Tamai I.; Membrane transporters as determinants of drug absorption and disposition, Xeno. Metab. Disp., 11(6): 642-650 (1996).

8) Takanaga H., Tamai I., Inaba S., Sai Y., Higashida H., Yamamoto H. and Tsuji A.: cDNA cloning and functional characterization of rat intestinal monocarboxylate transporter, Biochem. Biophys. Res. Comm., 217(1): 370-377 (1995).

9) Dain J. G., Fu E., Gorski J., Nicoletti J. and Scallen T. J.: Biotransformation of fluvastatin sodium in human, Drug Metab. Dispo., 21: 567-572 (1993).

10) Masuda N., Yanioka Y., Akasaka I. and Ohtawa M.: Metabolic fate of Fluvastatin, an inhibitor of HMG-CoA reductase (4): Stereoselective pharmacokinetics of the enantiomers of fluvastatin in rats, Xeno. Metab. Disp., 10(6): 779-798 (1995).

\begin{tabular}{|c|c|c|}
\hline 頁 & \multicolumn{1}{|c|}{ 正 } & \multicolumn{1}{c|}{ 誤 } \\
\hline 499 & 右段 $\quad 4$ 行目 : [Fluorobenzene-U-14 C $]$ & {$[$ Fluorbenzene-U-14C $]$} \\
\hline
\end{tabular}

